NASA/CR-1999-208888

Highlights of Aeroacoustics Research in the U.S.-1998

Ganesh Raman

Dynacs Engineering Co., Inc., Brook Park, Ohio

Dennis K. McLaughlin

Pennsylvania State University, University Park, Pennsylvania 
Since its founding, NASA has been dedicated to the advancement of aeronautics and space science. The NASA Scientific and Technical Information (STI) Program Office plays a key part in helping NASA maintain this important role.

The NASA STI Program Office is operated by Langley Research Center, the Lead Center for NASA's scientific and technical information. The NASA STI Program Office provides access to the NASA STI Database, the largest collection of aeronautical and space science STI in the world. The Program Office is also NASA's institutional mechanism for disseminating the results of its research and development activities. These results are published by NASA in the NASA STI Report Series, which includes the following report types:

- TECHNICAL PUBLICATION. Reports of completed research or a major significant phase of research that present the results of NASA programs and include extensive data or theoretical analysis. Includes compilations of significant scientific and technical data and information deemed to be of continuing reference value. NASA's counterpart of peerreviewed formal professional papers but has less stringent limitations on manuscript length and extent of graphic presentations.

- TECHNICAL MEMORANDUM. Scientific and technical findings that are preliminary or of specialized interest, e.g., quick release reports, working papers, and bibliographies that contain minimal annotation. Does not contain extensive analysis.

- CONTRACTOR REPORT. Scientific and technical findings by NASA-sponsored contractors and grantees.
- CONFERENCE PUBLICATION. Collected papers from scientific and technical conferences, symposia, seminars, or other meetings sponsored or cosponsored by NASA.

- SPECIAL PUBLICATION. Scientific, technical, or historical information from NASA programs, projects, and missions, often concerned with subjects having substantial public interest.

- TECHNICAL TRANSLATION. Englishlanguage translations of foreign scientific and technical material pertinent to NASA's mission.

Specialized services that complement the STI Program Office's diverse offerings include creating custom thesauri, building customized data bases, organizing and publishing research results ... even providing videos.

For more information about the NASA STI Program Office, see the following:

- Access the NASA STI Program Home Page at http://www.sti.nasa.gov

- E-mail your question via the Internet to help@sti.nasa.gov

- Fax your question to the NASA Access Help Desk at (301) 621-0134

- Telephone the NASA Access Help Desk at (301) 621-0390

- Write to:

NASA Access Help Desk

NASA Center for AeroSpace Information 7121 Standard Drive

Hanover, MD 21076 
NASA/CR-1999-208888

AIAA-99-1915

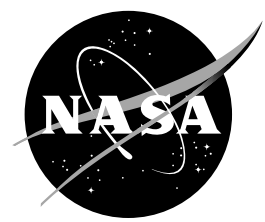

\section{Highlights of Aeroacoustics Research in the U.S.-1998}

Ganesh Raman

Dynacs Engineering Co., Inc., Brook Park, Ohio

Dennis K. McLaughlin

Pennsylvania State University, University Park, Pennsylvania

Prepared for the

5th Aeroacoustics Conference

sponsored by the American Institute of Aeronautics and Astronautics and the Confederation of European Aerospace Societies

Seattle, Washington, May 10-12, 1999

Prepared under Contract NAS3-98008

National Aeronautics and

Space Administration

Glenn Research Center 


\section{Acknowledgments}

The editors thank all those who contributed and graciously consented to the reproduction of illustrations.

Excerpts and photographs from NASA NP-1998-10-242-HQ also appear in this article.

Available from

NASA Center for Aerospace Information 7121 Standard Drive

Hanover, MD 21076

Price Code: A03
National Technical Information Service 5285 Port Royal Road Springfield, VA 22100 Price Code: A03 


\title{
Highlights of Aeroacoustics Research in the U.S. - 1998
}

\author{
Edited by: \\ Ganesh Raman ${ }^{1}$ \\ Dynacs Engineering Co., Inc. \\ Propulsion Analysis Section \\ NASA Glenn Research Center Group \\ 2001 Aerospace Parkway \\ Brook Park, Ohio 44142 \\ and \\ Dennis K. McLaughlin ${ }^{2}$ \\ Pennsylvania State University \\ Department of Aerospace Engineering \\ University Park, Pennsylvania 16802
}

With contributions from members of the AIAA Aeroacoustics Technical Committee and others including D.Huff, E. Envia, C. Hughes, J. Bridges, and N. Saiyed (NASA Glenn), R. Hixon (ICOMP), R.M. Nallasamy (Dynacs, Inc.), M. Ponton, J. Posey (NASA Langley), C.Horne and P. Soderman (NASA Ames), D. Reed, B. Shivashankara, A. Cain, and V. Kibens (Boeing), D. Mathews (Pratt \& Whitney), S. Martens (General Electric Aircraft Engines), S.H. Walker (AFOSR), M.J. Stanek (AFRL), K.K. Ahuja (GTRI), S.K. Lele (Stanford), J. Freund (UCLA), S. Dash (Craft Tech), P.J. Morris, L.N. Long (Penn State Univ.), and C.K.W. Tam (Florida State Univ.).

\begin{abstract}
Highlights of aeroacoustics research in the United States of America during 1998 are reported in a summary compiled from information provided by members of the Aeroacoustics Technical Committee of the American Institute of Aeronautics and Astronautics (AIAA) and other leading research groups in industry, national laboratories, and academia. The past few years have seen significant progress in aeroacoustics. Research has steadily progressed toward enhanced safety, noise benefits, and lower costs. Since industrial progress is generally not published in the
\end{abstract}

\footnotetext{
${ }^{1}$ Senior Research Engineer, Associate Fellow AIAA.

${ }^{2}$ Professor and Department Head, Associate Fellow AIAA.

Copyright (C 1999 by G. Raman and D.K. McLaughlin. Published by the American Institute of Aeronautics and Astronautics, Inc. with permission.
}

archival literature, it is particularly important to highlight these accomplishments. This year we chose to report on five topics of great interest to the aerospace industry including a synopsis of fundamental research at universities and national laboratories. The topics chosen are: (1) Advanced Subsonic Technology (AST), (2) High Speed Research (HSR), (3) Rotorcraft, (4) Weapons bay aeroacoustics control and (5) Academic research including Computational AeroAcoustics (CAA). Although the information presented in this review is not all encompassing we hope that the topics covered will provide some insights into aeroacoustics activity in the U.S. 


\section{Introduction}

Current aeroacoustic research can be roughly grouped into the five main areas noted above. This introductory section provides an overview of the material in this report. Technology developed for subsonic transport aircraft includes a scarfed inlet geometry, mixing devices for jet noise reduction, swept and leaned stator vanes for fan noise reduction, studies of airframe noise, acoustic liners, and facility upgrades.

The overall goal for the high-speed research program is to develop technology needed for the next generation supersonic transport aircraft. In the aeroacoustics area, NASA and several industrial companies are focusing on the developing mixer ejector exhaust nozzles. Specific elements include measurements of jet mixing and noise, and scaling efforts.

In the rotorcraft aeroacoustics area NASA centers lead the fundamental research development on prediction methodology for helicopter, as well as tilt rotor aeroacoustics. Predictions are being compared to flight test data.

Computational Aeroacoustics (CAA) continues to occupy an increasingly important role with academia/NASA teams leading the efforts.

Highlights of the research/development accomplishments in all the areas outlined above are summarized below.

\section{Noise Reduction Technology for Subsonic Transport Aircraft}

\subsection{Engine with Scarfed Inlet}

As part of NASA's AST Noise Reduction Program, Pratt \& Whitney has teamed with Boeing, BFG Aerospace, and the NASA Glenn and Langley Research Centers to test the newly certified PW4098 engine with a revolutionary low-noise, scarfed inlet provided by Boeing (see Fig. 1). Advanced technology noise treatment is installed in this inlet and in the engine's modified forward fan case, both of which provide broadband noise attenuation characteristics. Several noise tests were undertaken in November, 1998 and completion of remaining tests is scheduled for 1999. Significant noise reductions are expected from this engine/inlet combination. The PW4098 engine is currently one of the world's highest thrust certified engines, and will power new versions of the Boeing 777 aircraft.

\subsection{Jet Noise}

In the subsonic propulsion aeroacoustics technology arena, significant progress was made by General Electric Aircraft Engines in demonstrating, through extensive model scale test simulations under both NASA and IR\&D programs, the effectiveness of exhaust system mixing enhancement devices in substantially reducing jet noise while minimizing loss in exhaust system performance.

The effort to attenuate the noise from the exhaust portion of the engine (the nozzle) had a very significant test in 1997, demonstrating a 3-dB jet noise reduction. This joint research and laboratory test project among NASA, GE Aircraft Engines, and Pratt \& Whitney developed separate flow nozzle technology. Follow-on performance tests for the separate flow nozzles verified that $3 \mathrm{~dB}$ of jet noise suppression was achieved with minimal impact on thrust. Fig. 2 shows the separate flow nozzle that was tested at the NASA Glenn Aero-Acoustic Propulsion Laboratory.

The technology transfer from this test and other jet noise reduction tests emphasized both noise reduction technology and source diagnostic data to be used in future engine technology development.

\subsection{Engine Fan Noise}

NASA teamed with the Allison Engine Company to investigate new ways of reducing fan noise from turbofan engines. A 22-inch-scale model was built and tested (Woodward et al. (1999)) in the Glenn Research Center's 9x15-foot Low-Speed Wind Tunnel (see Fig. 3). This work was successful in helping the program meet a major milestone with a demonstrated 3 EPNdB (Effective Perceived Noise) fan noise reduction.

The noise reduction concept uses a highly swept and leaned geometry in the design of the outlet guide vanes. The tested sweep and lean configuration was designed at NASA Glenn Research Center (see Envia et al. (1996)) and built by the Allison Engine Company. Noise reduction occurs because sweep and lean alter the kinematic relationship between the rotor wakes and stator vanes and thus change the number of wake intersections experienced by a given vane. The change in the number of intersections, in turn, alters the distribution of the phase of the unsteady pressure induced on the vanes as a result of rotor wake impingement. Since the rotor-stator tone levels are related to the surface integrals of the vane unsteady surface pressure, the more phase variation there is in the vane unsteady pressure, the more cancellations will occur in the integral resulting in weaker interaction 
tones. The essential role of vane sweep and lean in modifying the distribution of the phase of the vane unsteady surface pressure is depicted in Fig. 4. The linkage between the wake-vane intersection picture (Figs. 4a-4c) and the vane unsteady pressure phase distribution (Figs. 4g-4i) is via the rotor wake upwash phase variation along the vane span (Figs. 4d-4f). In each of the three sets of plots, the top plot shows the baseline radial stator followed by a "favorable" combination and then a "detrimental" combination of sweep and lean. Clearly, when sweep and lean are chosen properly, significant variation in the phase of unsteady pressure occurs compared with the radial stator. For a more detailed discussion see Envia and Nallasamy (1998).

Significant progress was also made in identifying concepts for reducing fan tone and broadband noise, through extensive acoustic and aerodynamic performance trade studies. Preparations are being made for NASA-sponsored experimental wind tunnel validation of these concepts, in 1999. Additionally, experimental investigations of multiple mode Active Noise Control of fan stage interaction tones were carried out under NASA sponsorship, and significant reduction in these modes was demonstrated.

\subsection{Airframe Noise}

Airframe noise studies are growing as noise produced from flaps, slats, and landing gear in today's transport aircraft matches engine noise levels during approach. A recent accomplishment demonstrated technology to reduce flap noise, one of the three main airframe noise sources, by $4 \mathrm{~dB}$. NASA researchers in partnership with industry, academia, and the FAA accomplished this. Results of a series of wind tunnel experiments (see Fig. 5), guided by newly developed noise and flow prediction models, successfully demonstrated significant reductions from a new leading-edge slat design and three new flap designs. The airframe noise reduction program involved several NASA wind tunnels, each with unique performance capabilities. The Langley Research Center facilities used included the Quiet Flow Facility, the Basic Aerodynamics Research Tunnel (shown in Fig. 5), and the Low Turbulence Pressure Tunnel. Facilities used at the Ames Research Center included the 40x80-foot section of the National Full-Scale Aerodynamics Complex, the 7x10-foot Wind Tunnel, and the 12-foot Pressure Tunnel.

Much of the airframe noise is generated by separated and vortical flow produced by the high-lift system. A joint NASA-industry team has been investigating these noise sources to develop predictive models based on the flow physics. These models would enable designers to estimate changes in airframe noise from design changes in high-lift system components. In addition, detailed knowledge of the noise-generation physics opens the door to developing strategies to reduce or eliminate such noise with minimal impact on aircraft performance. One success has been to verify the physics of the noise generated by the side-edge of a trailing-edge flap. It had been postulated that a major component of the noise produced by such a flowfield came from fluctuations in the shear layer feeding the trailing vortex. Using a combination of (1) a highly detailed Reynolds - Averaged Navier - Stokes computations of the steady flowfield, (2) an approximate numerical simulation of the fluctuations developing in that flowfield, and (3) a Lighthill acoustic-analogy computation of the sound generated by those fluctuations, NASA Langley researchers have successfully predicted the shape of the noise spectrum produced by a simple part-span flap model. These first-of-a-kind computations are in good agreement with experimental results, and the postulate noted above.

\subsection{Acoustic Liners}

Wind tunnel testing of a low-speed fan with advanced acoustic liners at NASA successfully demonstrated a major program goal for 1-EPNdB liner suppression improvement over current liners. Fig. 6 shows Pratt \& Whitney's low speed fan with advanced acoustic liners installed in NASA Glenn's 9x15-foot wind tunnel. An advanced active noise control concept was also investigated, which demonstrated that it is technically feasible to further reduce fan tones by as much as $10 \mathrm{~dB}$.

\subsection{Facility Upgrades}

The acoustic modernization project for the $40 \times 80$-foot Wind Tunnel test section has been completed, and the facility is being readied for service. The project involved installing of a new $1.1 \mathrm{~m}$ deep acoustic lining that encircles the test section and extends $24 \mathrm{~m}$ streamwise, joining a shallower lining that extends $6 \mathrm{~m}$ into the diffuser inlet. Fiberglass wedges were recessed behind a porous interface so that the nominal test section dimensions were retained. The new liner now facilitates effective and accurate conventional and phased array microphone measurements through the frequency range from $200 \mathrm{~Hz}$ to $50 \mathrm{kHz}$. The drive-fan control system was also upgraded to allow improved operation at low rotational speed when minimal noise is desired. Integrated system tests are underway prior to the start of research testing. The wind tunnel has a maximum airspeed of 300 knots and is used primarily for aerodynamic and aeroacoustic investigations of smalland large-scale aircraft models during simulated landing or takeoff operations. The models, which generally range from $25 \%$ to $55 \%$ of full scale, are often powered with propulsion simulators or actual engines for evaluations of 
propulsion/airframe integration effects. Fig. 7 shows the NASA Ames anechoic facility after installation of a new acoustic lining. The entire crew responsible for lining design and performance testing pictured in the tunnel emphasize the enormous cross-section of this facility.

\section{High Speed Research}

\subsection{Measurements of Mixing and Noise}

Significant progress has been made in the area of high speed aeroacoustics at GE Aircraft Engines under the High Speed Research program sponsored by NASA during 1998. One area is the detailed measurements of the velocity and vorticity field produced by the mixer in the mixer/ejector exhaust nozzle for the HSCT. These measurements, internal to the ejector, provide a better understanding of what various types of mixing enhancement devices on the mixer are doing to the flow field and ultimately to the radiated acoustic field.

\subsection{Scaling Efforts}

Another major stride was made in the analysis of scaling and flight effects. An approximately one half-scale mixer/ejector exhaust nozzle was statically tested behind an F100 engine at Pratt \& Whitney. This is a major undertaking to determine how well small scale data acquired under the HSR program can be scaled and corrected for flight effects to a product size. All of these experiments are being performed with careful evaluations of the thrust penalties associated with each configuration. Boeing and Georgia Tech researchers are leading the effort to identify noise source locations including the ability to determine the portion of noise produced inside the ejector as distinguished from that produced by the mixing in the jet downstream of the ejector nozzle. Fig. 8 shows the Large-Scale Model (LSM) tests of quiet nozzle technology for future supersonic commercial aircraft.

\section{Rotorcraft}

\subsection{Prediction Methodology}

Farassat and Brentner (1998) derived a new analytic result for efficient prediction of the noise from subsonic and supersonic volume quadrupoles of helicopter rotors. The new result, designated as Formulation Q2 is a particularly simple analytic expression based on an earlier result of the authors' predecessor as Formulation Q1 where the quadrupole sources are integrated along the normal direction to rotor plane and then treated as surface sources. The simplicity of the new formulation is due to the choice of the selection of the frame of the reference of the source description in taking observer time derivatives of two three dimensional (two space and one time) integrals. The new formulation is incorporated in a new version of the helicopter noise prediction code WOPWOP called WOPWOP2+. Comparison of measured and predicted acoustic data for cases where delocalization occurs is excellent.

In helicopter rotor noise prediction, part of the surface on which the aerodynamic data are specified can travel at supersonic speed. The current noise prediction formulations, using the Ffowcs Williams-Hawkings (FW-H) equation for penetrable surfaces or the Kirchhoff method are very complicated for supersonically moving surface sources. The corresponding subsonic result known as Formulation $1 \mathrm{~A}$ is very simple but contains a singularity when the surface moves at supersonic speed. Recently, Farassat et al. (1998) have derived a new analytic expression, designated as Formulation 4 of Langley, for prediction of the noise from both subsonic and supersonic surface sources. This Formulation is as simple as Formulation $1 \mathrm{~A}$ and is singularity-free. However, it involves surface curvature terms and line integrals around the edge of the source panels that are absent from the subsonic formulation.

\subsection{NATO CCMS Helicopter Noise Test}

A NATO CCMS (Committee on the Current Challenges of Modern Society) Helicopter Noise Flight Test was conducted at the Canadian Forces Base, Moose Jaw, Saskatchewan, in June 1998. Acoustic data were acquired by organizations from the U.S. (NASA LaRC and Wright Patterson AFB), the U.K. (Royal Air Force and Defense Evaluation and Research Agency), Germany (Federal Environment Agency), Norway (SINTEF DELAB), and Denmark (Delta Acoustics and Vibration). In addition, Wright Patterson AFB personnel acquired GPS tracking and aircraft attitude data while NASA LaRC personnel acquired weather data. The overall purpose for the test was to develop an international standard for measuring and analyzing the noise directivity characteristics of helicopters. The NATO countries will also define a common data base format that will be adopted as the international standard. In addition, NASA Langley will use the data to verify the propagation algorithms that are contained in LaRC's Rotor Noise Model (RNM). Data were acquired for 158 runs including 66 level flyovers, 53 approaches $\left(3^{\circ}, 6^{\circ}, 9^{\circ}\right.$, and $12^{\circ}$ descent angles $)$, 36 take-offs $(500,1000 \& 1500 \mathrm{ft} / \mathrm{min}$ ascent rates), and three hovers (on ground flat blade pitch, IGE, and OGE). 


\subsection{XV-15 Terminal Area Acoustics Flight Test Program}

The second in a series of three XV-15 Terminal Area Acoustics flight tests was conducted at Waxahachie, Texas, (see Fig. 9). The overall program objective was to determine flight procedures for tiltrotors that are quiet, safe, and easy to fly. The program approach was to measure the far-field noise of a tiltrotor during terminal area operations. These measurements would help develop low noise operating procedures by optimizing the nacelle tilt schedule and the approach profile to reduce the radiated noise. The far-field acoustic database will also validate noise prediction methodologies and community noise impact models. The first test, conducted in the fall 1995, showed that the Sound Exposure Level (SEL) can be reduced by up to $10 \mathrm{~dB}$ by varying the nacelle angle, and the noise footprint can be significantly altered by modifying the approach profile. The 1995 test also showed that there really is no noise problem for tiltrotor take-offs. The 1997 test utilized a 37 microphone large area array (2000 feet wide by 9000 feet long) to measure the noise footprints for approaches to hover. The variable airspeed, nacelle angle, and glideslope approaches blended handling quality requirements with noise reduction to assure realistic IFR approaches

\section{Weapons Bay Aeroacoustic Control}

Air Force Research Laboratories (AFRL), Air Force Office of Scientific Research (AFOSR), NASA, Naval Air Weapons Center (NAWC), and DERA (UK) have all initiated new coordinated weapons bay aeroacoustic control programs to enhance the ability to dispense weapons over a larger flight envelope without fatigue failure. New experiments have been conducted, a number of simulation efforts are in place using LES methodology, and flight tests are planned for the near future. A consortium entitled Active Robust ConTrol of Internal Cavities (ARCTIC) made up of the government agencies listed, and including major airframe contractors, small companies, and universities, was developed to help focus efforts and enhance coordination.

Craft Tech is adapting the capability of current generation CFD codes to simulate the aeroacoustic environment in cavities. It has been shown that a crude grid very large eddy simulation framework (VLES) provides good agreement with pressure spectra for frequencies of interest (up to $20 \mathrm{kHz}$ ), whereas use of conventional timeaveraged models (algebraic or two-equation) results in poor quality, over-damped comparisons. Current research is focused on analyzing cavities with included stores, on simulating store expulsion in a severe aeroacoustic environment, and on active/passive control of pressure oscillations.

\section{Academic Research}

\subsection{New Liner Technology}

An advanced liner testing facility was built by GTRI researchers (see Ahuja and Gaeta (1997); Gaeta and Ahuja (1997)) to test the sound absorbing characteristics of acoustics liners as a function of flow velocity. This facility has been used for NASA projects and also for industrial sponsors to determine the performance of various liners. GTRI patented acoustic hollow beads as broadband noise absorbers for high temperature applications (see Fig. 10). The tiny, hollow spheres developed at the Georgia Institute of Technology nearly ten years ago for high-temperature insulation also offer competitive noise-absorption properties, recent studies show. Researchers are using the spheres to create an acoustic liner material they believe has several advantages over existing materials, including its ability to withstand temperatures over $2,000^{\circ} \mathrm{F}$. Most other liner materials come in preshaped forms. The more versatile spheres could be poured into existing structures-from the walls of homes, hotels and concert halls to the framework of aircraft and automobiles. They could even be encased in a quilt-like fabric to make portable curtains and blankets for use in noisy factories or at roadway construction sites, where permanent structures are not needed.

\subsection{Screech Simulation}

Numerical simulations of supersonic jet screech, an intense form of shock noise, are being carried out at Stanford University by Manning and Lele (1998). Screech accelerates structural fatigue in supersonic fighter aircraft, so it is important to develop methods for predicting the amplitude of its sound field. Recently, an important milestone was achieved in the understanding of the screech generation process consisting of instability wave vortices convecting in a supersonic, free jet shear layer and interacting with an oblique shock. Numerical simulations of the generation process reveal important details of the shock motion, acoustic wave formation, and acoustic wave propagation and will provide a firm basis for developing improved shock noise generation models. Fig. 11 depicts an instability wave/shock interaction and resulting acoustic wave production. 
Development of highly accurate and efficient Computational Aeroacoustics methods has been actively pursued at the Florida State University. Recently, these methods have been used to investigate, by numerical simulation, a number of aeroacoustics problems in the areas of jet noise, airframe noise and liner acoustics. Figure 12 illustrates a comparison between the computed unsteady shock cell structure and large scale instability waves/toroidal vortices of a screeching jet and the experimental observations (see Shen and Tam (1998)).

\subsection{Numerical Simulations}

New advances in numerical simulations of turbulent flow and aeroacoustic phenomena can be classified as direct numerical simulations or large eddy simulations. Researchers at Stanford and (recently) UCLA have been leading the efforts on direct numerical simulation. The Stanford work included the simulation of a Mach 1.92 jet and its sound field (Freund et al. (1998)), Fig. 13. In follow-on work UCLA undertook the study of a $\mathrm{M}=0.9$ jet whose experimental conditions match the experiments of Stromberg et al. (1980). These computations follow similar but considerably simpler methods using the Euler equations that have been ongoing at NASA Glenn Research Center for some time: e.g., Hixon et al. (1997). The data generated from the simulations will be used to probe the physics of jet noise generation and enhance our understanding of semi-empirical models as they are developed.

Because direct numerical simulations can only work at low Reynolds numbers one has to resort to large eddy simulations for flows of engineering interest. Even though such large eddy computations require much smaller computer resources, they can still be significant if scales in the inertial subrange are to be resolved. However, solutions of the Reynolds-Averaged Navier-Stokes (RANS) equations, with an appropriate turbulence model, can provide an efficient and accurate solution for time-averaged flow. At Penn State University, Morris et al. (1997, 1998) have devised a new formulation that recasts the Navier-Stokes equations into equations for the nonlinear perturbations about the RANS approximation to the mean flow. The instantaneous fluctuations are decomposed into a time-averaged component, a resolved large-scale perturbation about this mean, and an unresolved small-scale perturbation. A subgrid scale (SGS) model is used to describe the unresolved scales. The resulting equations are solved on parallel computers using a domain decomposition strategy. A polar type of grid is used with approximately 2 million total grid points. Clustering occurs in the jet shear layer, and the grid is stretched in the axial direction. A spectral discretization is used in the azimuthal direction. The jet far field is computed by both direct simulations and with a Ffowcs Williams and Hawkings method. Calculations have been performed for both circular and rectangular jets. Figure 14 shows simulations of both the sound pressure field and an iso-vorticity surface for an aspect-ratio-2, unheated, Mach 1.66, jet. Shown are instantaneous pressure contours in one major axis (x-y) and one minor axis plane (x-z) of the jet and a vorticity magntiude isosurface at $\omega=0.1 u_{j} / b_{o}$, where $b_{o}$ is the initial shear layer thickness. The peak radiation is observed at 25 degrees to the downstream direction and the main source region is approximately 20 equivalent radii downstream of the nozzle. Note the logarithemic mapping of the pressure contours.

At ICOMP (Institute for Computational Mechanics in Propulsion), research has focused on the problem of predicting the far-field noise generated by a circular jet at $M=1.4$ in a $M=0.4$ flight stream (see Hixon et al. (1998) and Fig. 15). The problem has been divided into three parts, reflecting the parts of the physical problem: First, the nozzle geometry determines the characteristics of the jet exhaust flow. Second, the unsteady exhaust plume itself generates noise. Third, the internal noise from the nozzle and the external noise from the exhaust plume radiate out to the far field.

The second and third parts of the problem were attacked first. A large eddy simulation approach is used to numerically solve the unsteady, nonlinear near-field flow (Shih et al. (1998)) and a Kirchhoff method is used to propagate the acoustic signals to the far-field (Shih et al. (1997)). In order to incorporate the nozzle geometry into the calculation, the code has been reformulated as a structured multiblock solver for curvilinear grids.

Throughout this effort, it has been recognized that numerical issues will determine the accuracy of the solution. Thus, much work has been done on testing and improving the discretization, filtering, curvilinear performance, nonlinear performance, and boundary conditions.

\subsection{Prediction of Engine Inlet Noise}

The prediction (and reduction) of engine noise is an important and challenging problem, particularly for large ducted fans. The computational techniques utilized in the past have often used simplifying assumptions such as elementary models of blade/vane interaction source terms, approximate nacelle geometries, and linear equations. L.N. Long and his co-workers at Penn State University have developed parallel computer codes to solve the 3-D Euler/Navier-Stokes equations using higher-order accurate methods that model more of the physics of the problem. Figure 16 shows the noise radiation from a JT15D engine inlet, from source terms located on a plane 
inside the engine. These new methods allow one to predict nonlinear, 3-D effects (e.g. scarfed inlets), and realistic propagation through shear layers. Ozyoruk et al. (1998) describes how to implement impedance boundary conditions into time-marching CAA codes while Liu and Long (1998) describes a direct simulation of the liner problem using the NLDE equations. Chyczewski et al. (1998) discuss how one can implement time-accurate boundary conditions, which are very important for obtaining accurate exhaust simulations. These methods are typically used in a region very close to the engine, and the far-field is predicted using Kirchhoff or Ffowcs Williams-Hawkings methods. Penn State plans to combine their inlet radiation codes and their turbulent jet codes in the near future, to simulate the entire engine noise problem. They plan to use existing CFD codes (e.g., CFL3D) for the mean flow predictions, and then a CAA code for the radiation.

The computational power of high performance computers needs to be exploited in order for realistic CAA calculations to be performed. One of the most interesting recent developments has been inexpensive clusters of PC's, often called Beowulf computers. These are very cost-effective, department-level supercomputers. These machines, using fast ethernet or ATM networks, and Linux as the operating system, are particularly well suited to aeroacoustic calculations, since they can be performed using MPI and domain decomposition. Performance is competitive with large parallel computers for some applications, and the PC clusters cost only about onetenth of a conventional, large parallel computer. A successful implementation of this technology is described in Long et al. (1998).

\subsection{Towards Development of Active Control Techniques for Jet Noise Reduction}

As a rationale in developing of an active control technique to reduce jet noise, Seiner (1998) offers a framework for a dynamical systems approach that uses a low-dimensional model for the two-point, turbulent velocity correlations in a shear layer as the undergirding for designing active controllers. He postulates that this low-dimensional model could be formulated using the Proper Orthogonal Decomposition modes extracted from data acquired via the Particle Image Velocimetry (PIV) technique. Fig. 17 shows the PIV setup in the NASA Langley low speed aeroacoustic wind tunnel.

Because of the noise benefit associated with high bypass ratio turbo-fan engines, an experiment was conducted in the NASA Langley low speed aeroacoustic wind tunnel on a co-annular axisymmetric nozzle configuration. Using PIV, initial velocity field measurements have been made for several core-to-fan velocity ratios above and below unity. Each nozzle streams's Mach number ranged from 0.30 to 0.85 , and the freestream tunnel Mach number remained constant at 0.10 . The data will be further processed to determine the turbulent jet characteristics of importance to noise generation. This experiment represents an initial step in applying PIV to large-scale realistic nozzle configurations.

\section{Concluding Remarks}

We reported briefly on selected topics of aeroacoustics research in the U.S. during 1998. Examples of good progress in the areas of jet, fan, airframe and helicopter noise as well as liner design were provided. In addition, we described important developments in the fields of Computational AeroAcoustics (CAA) and Direct Numerical Simulation (DNS). In the next few years we look forward to seeing major strides in noise reduction technology and our ability to compute situations of aeroacoustics interest.

During 1998 the American Institute of Aeronautics and Astronautics (AIAA) organized several programs in aeroacoustics. About 40 papers were presented in the aeroacoustics sessions at the $36^{\text {th }}$ Aerospace Sciences Conference and Exhibit held at Reno, NV, in Jan. 1998. The Confederation of European Aerospace Societies (CEAS) and AIAA held their fourth successful joint conference at Toulouse, France, in June 1998. About 180 papers were presented at that conference.

Finally, the community was saddened by the untimely death of Sir James Lighthill, the foremost aeroacoustics pioneer, so soon after he received the new CEAS aeroacoustics award at the CEAS/AIAA meeting held at Toulouse, France.

\section{References}

Aeronautics and Space Transportation Technology, Three Pillars for Success. NASA Annual Progress Report 1997-1998. Publication of the NASA Office of Aeronautics and Space Transportation Technology, Code R, NASA HQ, NP-1998-10-242-HQ.

Ahuja, K.K., and Gaeta, R.J., Jr. 1997 A New WideBand Acoustic Liner with High Temperature Capability. AIAA Paper 97-1701.

Chyczewski, T., Long, L.N., and Morris, P. 1998 Numerical Study of Nozzle Exit Condition Effects on Jet Development. AIAA Journal, Vol 36, 986-993. 
Envia, E., Huff, D.L., and Morrison, C.R. 1996 Analytical Assessment of Stator Sweep and Lean in Reducing RotorStator Tone Noise. AIAA Paper 96-1791.

Envia, E., and Nallasamy, M. 1998 Design Selection and Analysis of a Swept and Leaned Stator Concept. NASA/TM-1998-208662.

Farassat, F., and Brentner, K.S. 1998 Supersonic Quadrupole Noise Theory for High-Speed Helicopter Rotors. J. Sound Vib. Vol. 218, 481-500.

Farassat, F., Brentner, K.S., and Dunn, M.H. 1998 A Study of Supersonic Surface Sources - The Ffowcs Williams-Hawkings Equation and the Kirchoff Formula. AIAA Paper 98-2375.

Freund, J., Lele, S., and Moin, P. 1998 Direct Numerical Simulation of a Mach 1.92 Turbulent Jet and Its Sound Field. AIAA Paper No. 98-2291.

Gaeta, R.J., Jr. and Ahuja, K.K. 1997 A Unique FlowDuct Facility to Measure Liner Performance in Cold and Heated Flows. AIAA Paper 97-1700.

Hixon, R., Shih, S.H., and Mankbadi, R.R. 1997 Numerical Simulation of the Effect of Heating on Supersonic Jet Noise. NASA CR-202338 (ICOMP-97-04).

Hixon, R., Shih, S.H., Mankbadi, R.R., and Scott, J.R. 1998 Time-Domain Solution of the Airfoil Gust Problem Using a High-Order Compact Scheme. AIAA Paper 98-3241.

Liu, J., and Long, L.N. 1998 Direct Aeroacoustic and Aerodynamic Simulation of Multi-Hole Engine Liners. AIAA Paper 98-2330.

Long, L.N., Morris, P.J., Morooney, K., and Kellogg, S. 1998 The Teaching and Learning of High Performance Computing. Journal of Engineering Education, Vol. 87.
Manning, T.A., and Lele, S.K. 1998 Numerical Simulations of Shock-Vortex Interactions in Supersonic Jet Screech. AIAA Paper 98-0282.

Morris, P.J., Long, L.N., Bangalore, A., and Wang, Q. 1997 A Parallel Three-Dimensional Computational Aeroacoustics Method Using Nonlinear Disturbance Equations. J. Computational Physics, Vol. 133, 56-74.

Morris, P.J., Long, L.N., Wang, Q., Scheidegger, T., and Pilon, A.R. 1998 High Speed Jet Noise Simulations. AIAA/CEAS Paper 98-2290.

Ozyoruk, Y., Long, L.N., and Jones, M.G. 1998 TimeDomain Numerical Simulation of a Flow-Impedance Tube. Journal of Computational Physics, Vol. 146, 29-57.

Seiner, J.M. 1998 A New Rational Approach to Jet Noise Reduction. Theoretical and Computational Fluid Dynamics, Vol. 10, 373-383.

Shen, H., and Tam, C.K.W. 1998 Numerical Simulation of the Generation of Axisymmetric Mode Jet Screech Tones. AIAA Journal, Vol. 36, 1801-1807.

Shih, S.H., Hixon, R., Povinelli, L.A., and Mankbadi, R.R. 1998 Large-Scale Simulation of Supersonic Jet Noise. AIAA Paper 98-3014.

Shih, S.H., Hixon, R., Mankbadi, R.R., Pilon, A., and Lyrintzis, A. 1997 Evaluation of Far-Field Jet Noise Prediction Methods. AIAA Paper 97-0282.

Stromberg, J.L., McLaughlin, D.K., and Troutt, T.R. 1980 Flow Field and Acoustic Properties of a Mach Number 0.9 Jet at Low Reynolds Number. J. Sound Vib. Vol. 72, 159-176.

Woodward, R.P., Elliott, D.M., Hughes, C.E., and Berton, J.J. 1999 Benefits of Swept and Leaned Stators for Fan Noise Reduction. AIAA Paper 99-0479. 


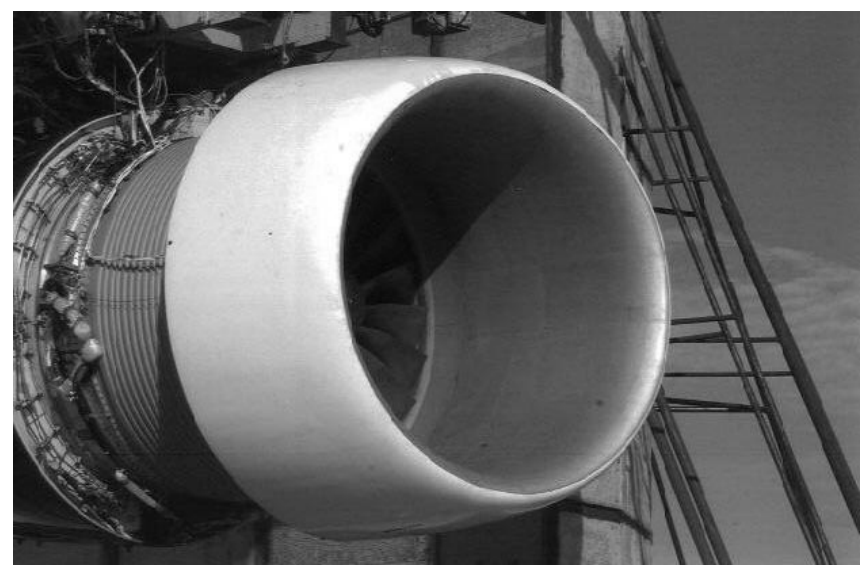

Figure 1. Boeing's advanced, low-noise, scarfed inlet mounted on Pratt \& Whitney's PW 4098 engine. Photo courtesy of Pratt \& Whitney.

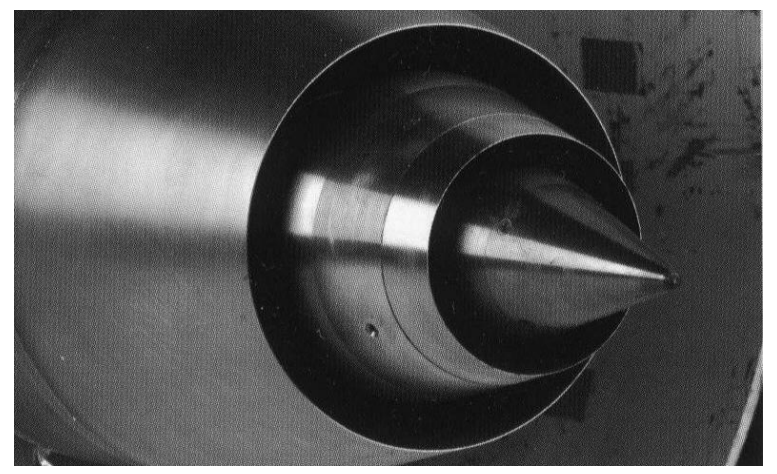

Figure 2. Separate flow nozzle technology tested at the NASA Glenn Aero-Acoustic Propulsion Laboratory. Photo courtesy of NASA.

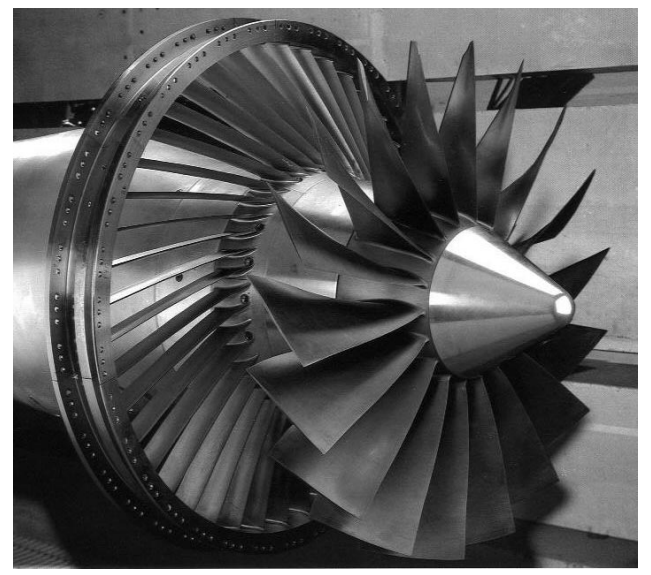

Figure 3. New technology for reducing fan blade noise using swept and lean stator vane technology. NASA/Allison scale model installed in the NASA Glenn 9x15-foot wind tunnel. Photo courtesy of NASA. 


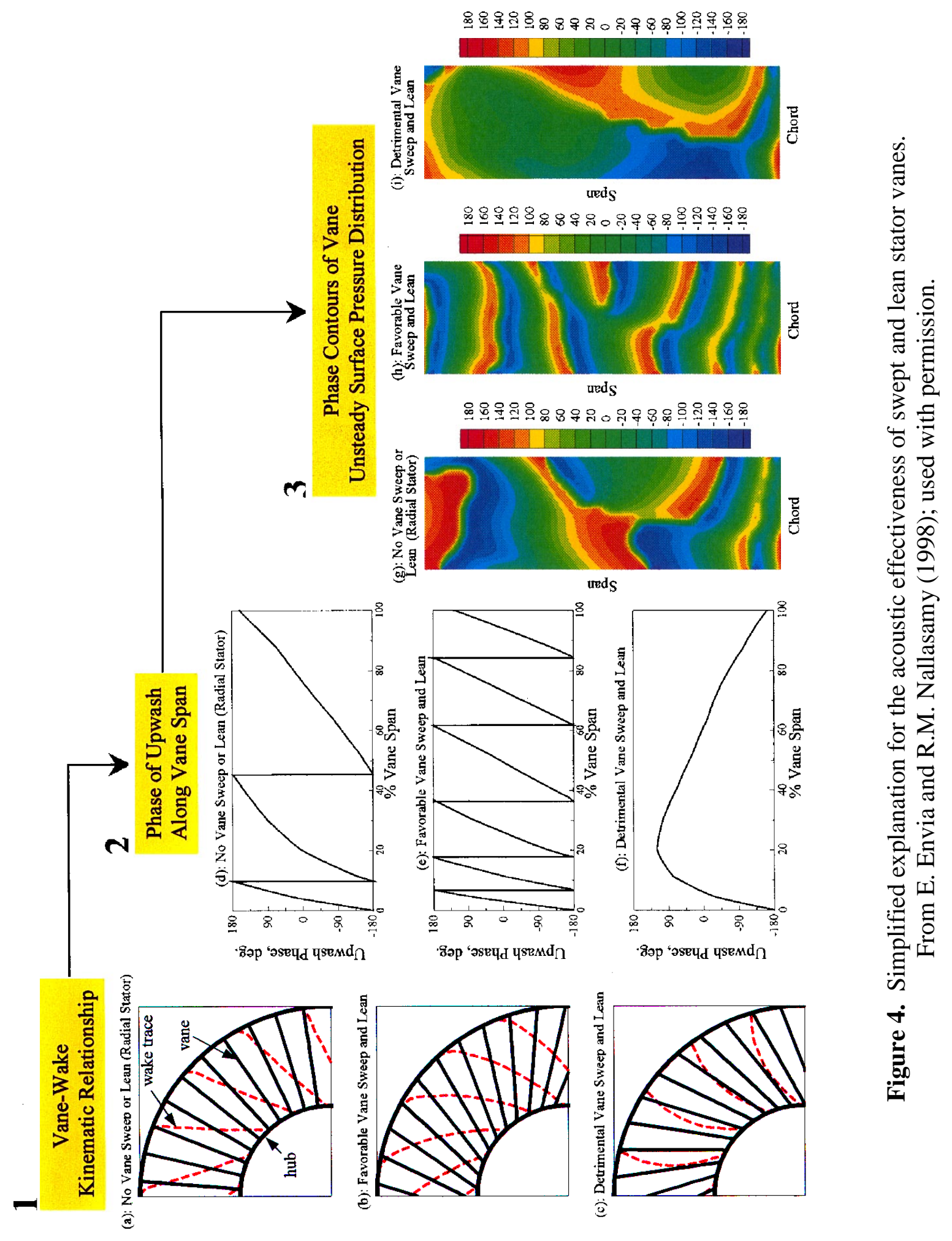




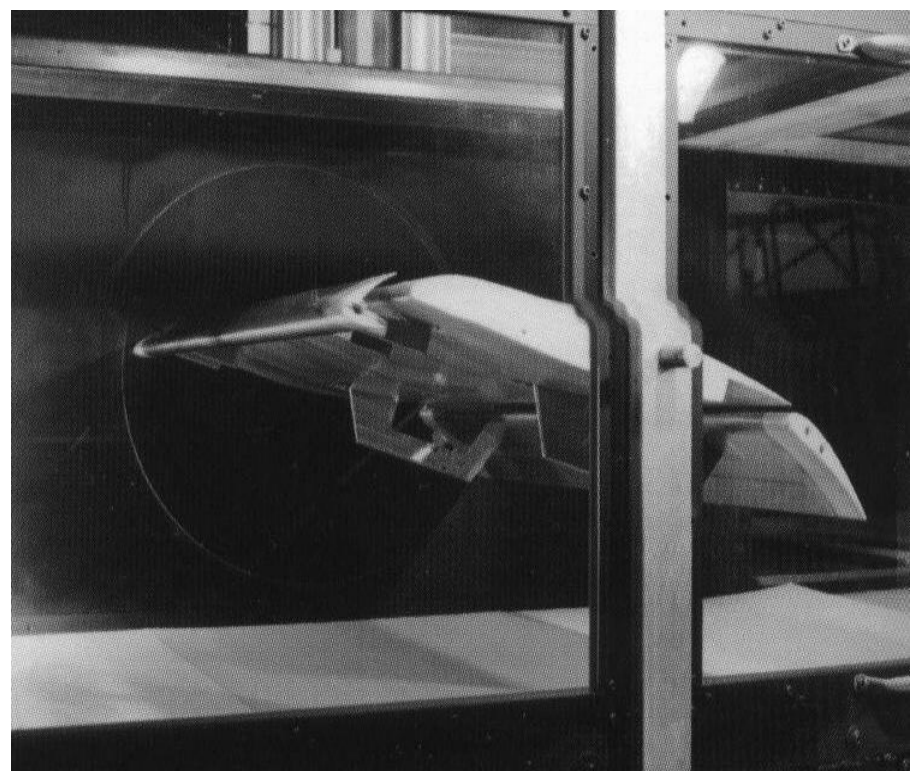

Figure 5. Flap noise reduction technology demonstrated at the NASA Langley basic aerodynamics research tunnel. Photo courtesy of NASA.

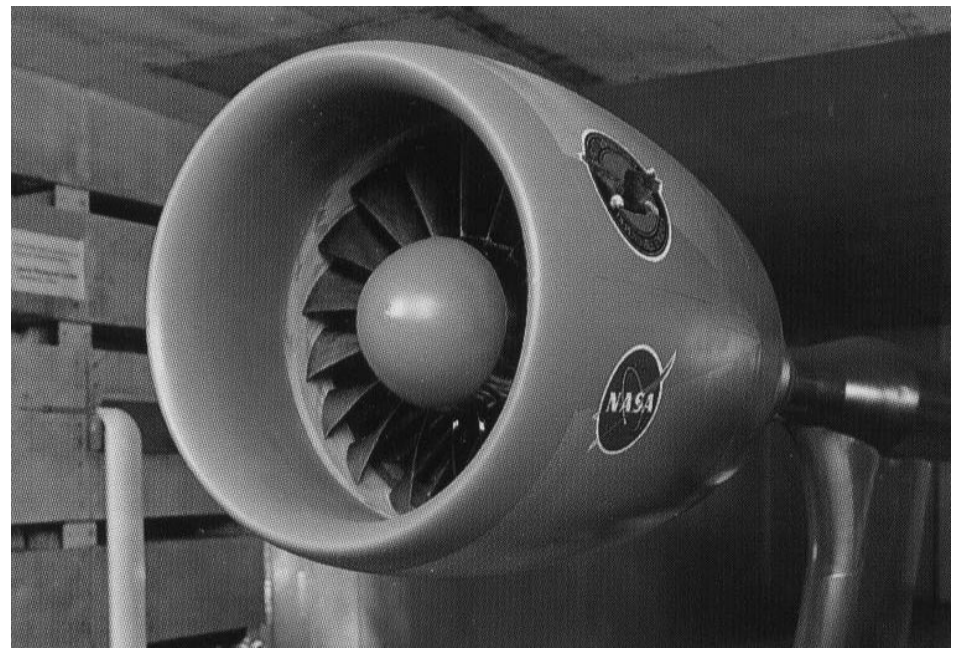

Figure 6. Pratt \& Whitney's low speed fan with advanced acoustic liners was tested at NASA Glenn's 9x15-foot wind tunnel. Photo courtesy of NASA. 


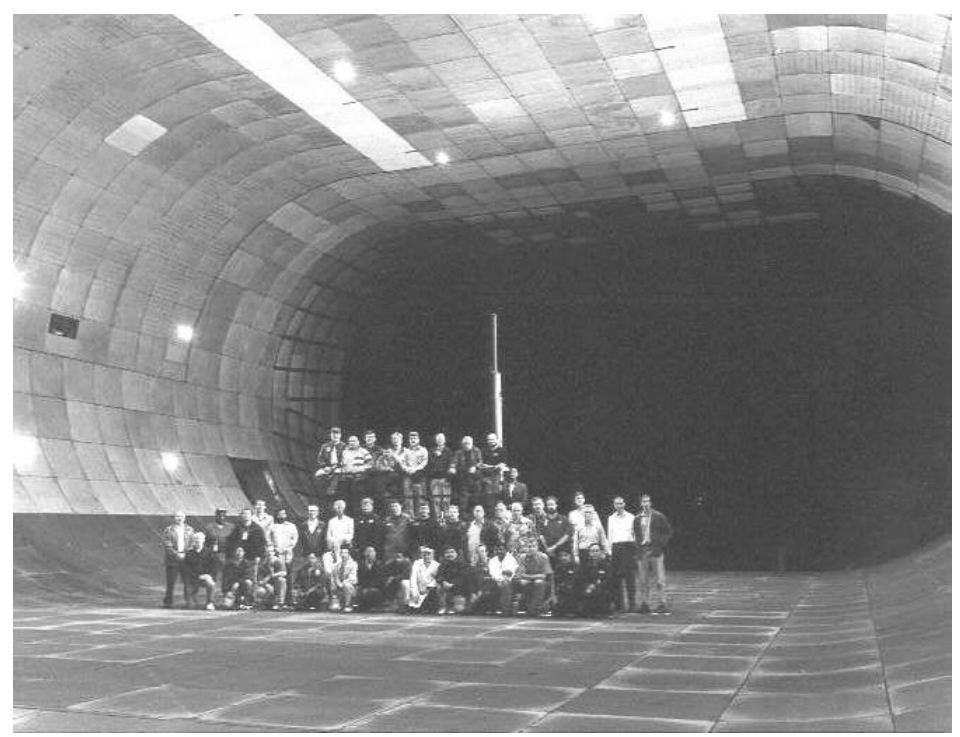

Figure 7. The NASA Ames 40x80-foot anechoic facility shown after installation of a new acoustic lining. The entire crew responsible for lining design and performance testing pictured in the tunnel emphasize the enormous cross-section of the facility.

Photo courtesy of NASA.

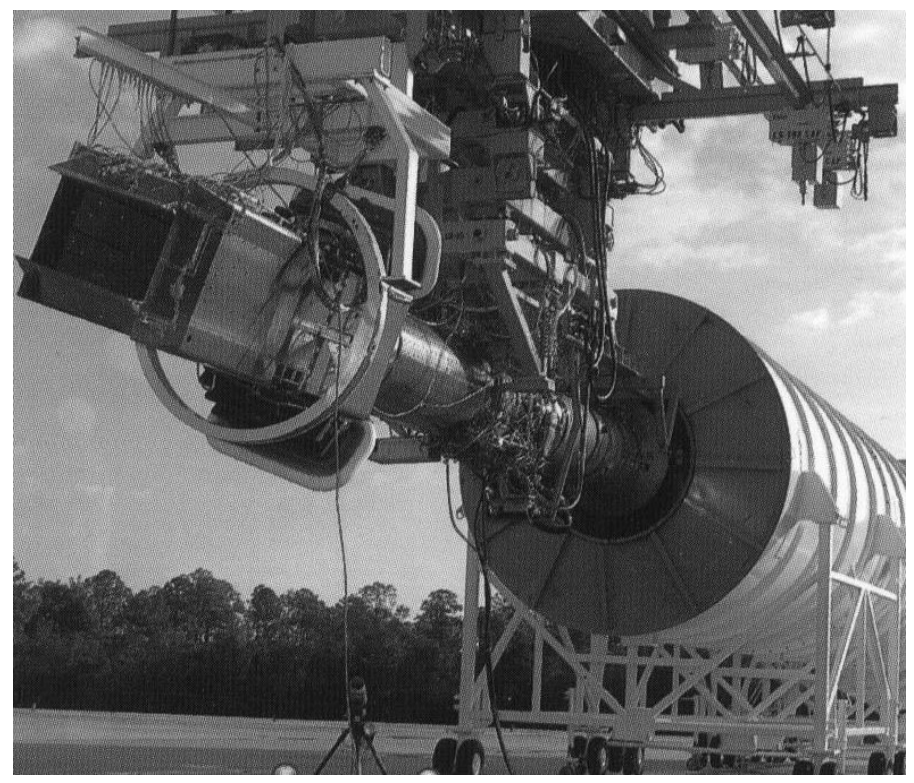

Figure 8. Large-Scale Model (LSM) tests of the General Electric/Pratt \& Whitney quiet nozzle technology for future supersonic commercial aircraft. Photo courtesy of NASA. 


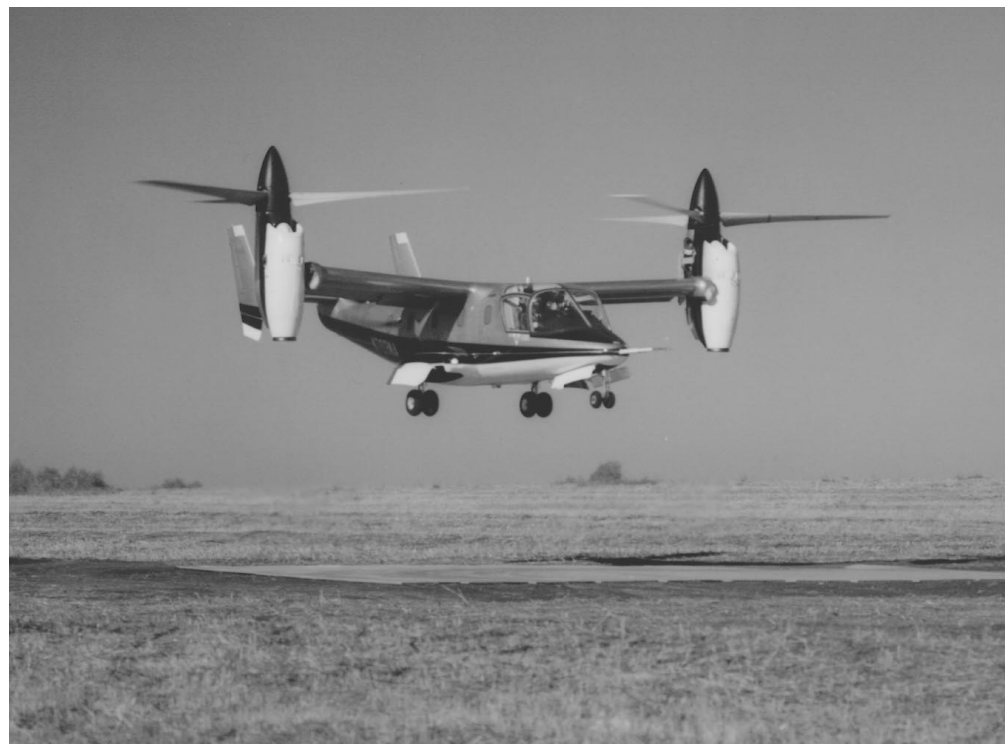

Figure 9. Terminal area acoustics flight tests on the XV-15 at Waxahachie, Texas. Photo courtesy of NASA.

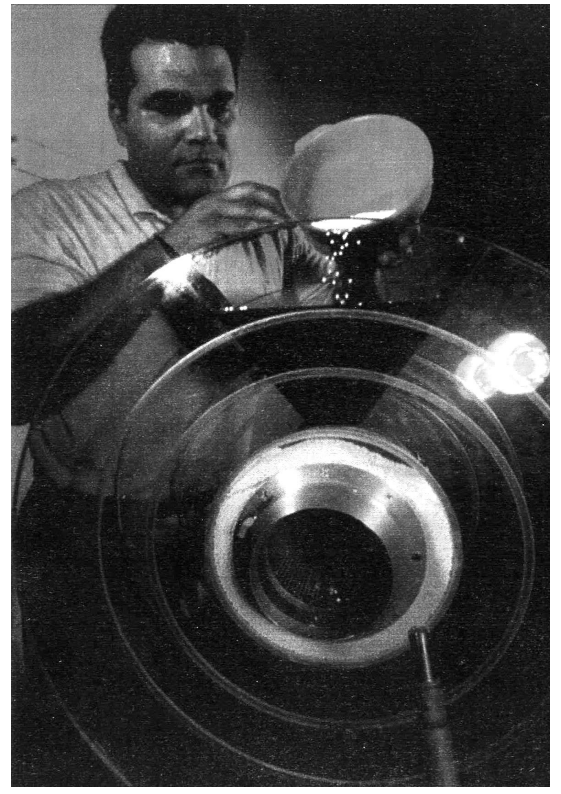

Figure 10. New acoustic liner material consisting of tiny white spheres developed by Georgia Tech. researchers. CK.K. Ahuja and R.J. Gaeta; used with permission. 

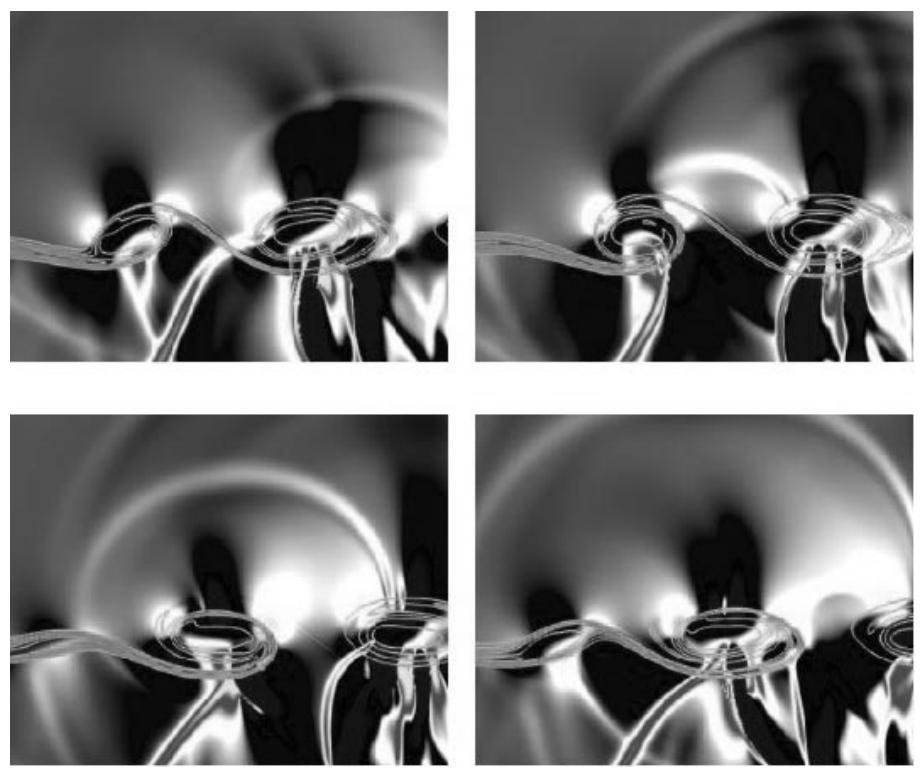

Figure 11. Instability wave/shock interaction and resulting acoustic wave production. CT. Manning and S.K. Lele (1998); used with permission.

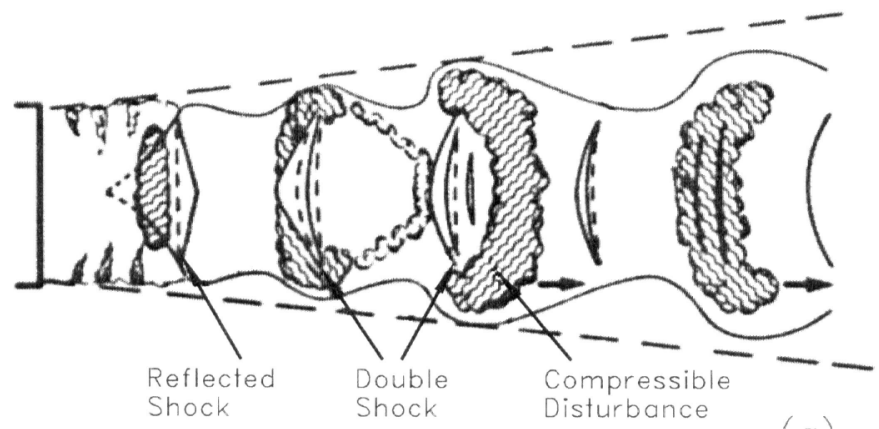

a) Experimental observation by Westley and Woolley

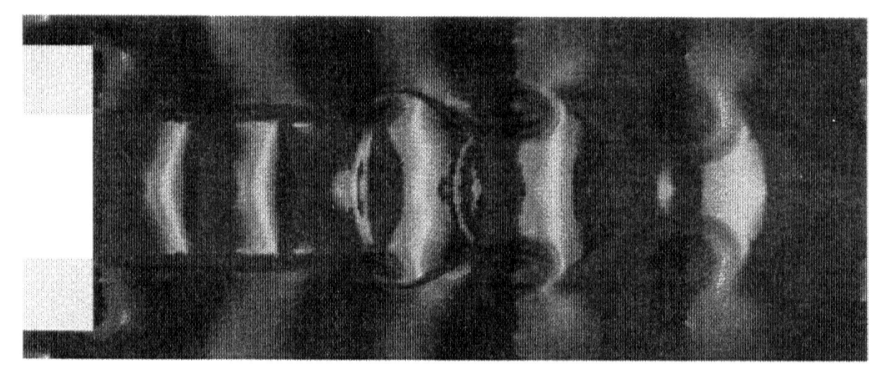

b) Numerical simulation

(b)

Figure 12. Comparison between computed unsteady shock-containing screeching jet and experimental observations of Westley and Wooley. (CH. Shen and C.K.W. Tam (1998); used with permission. 


\section{Mach 1.92 Jet With Sound Field}

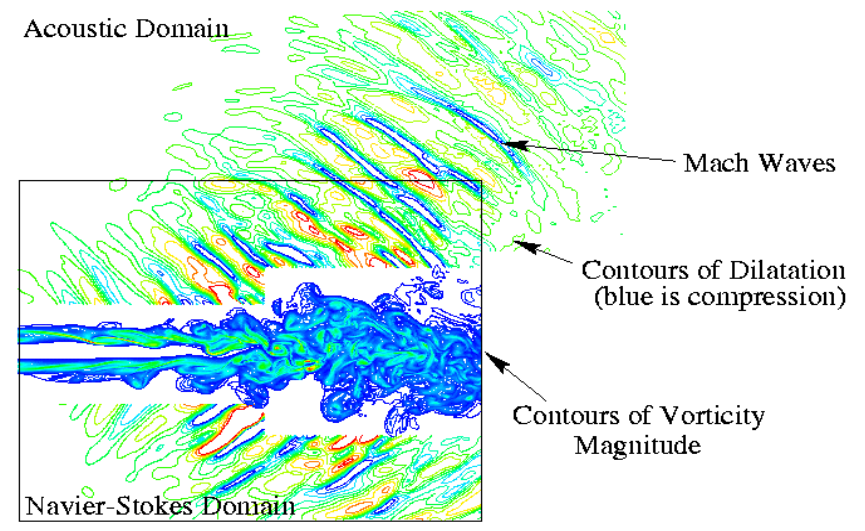

Figure 13. Computation of $M=1.92$ jet and its sound field. CJ. Freund (1998); used with permission.

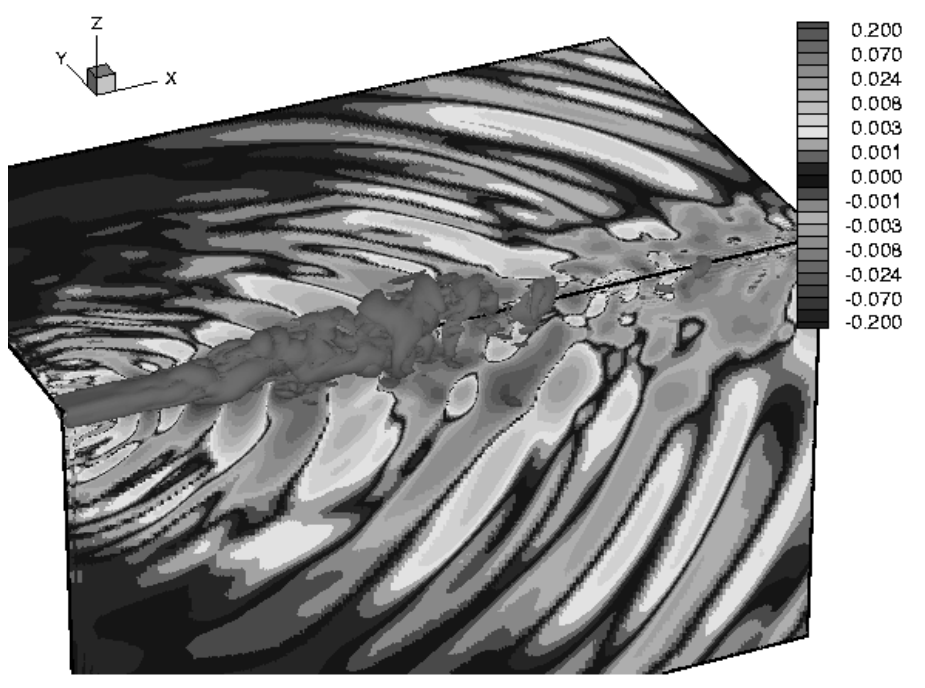

Figure 14. Simulated radiation pressure field for a rectangular jet at $M=1.66$. Shown are instantaneous pressure contours and a vorticity isosurface. CP.J. Morris (1998); used with permission. 


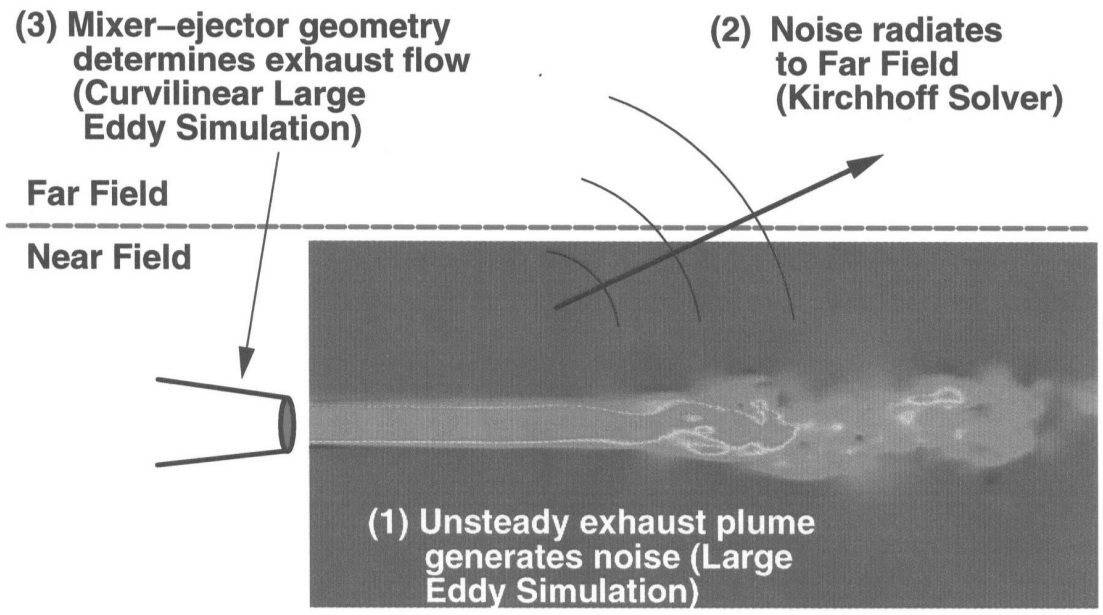

Figure 15. Prediction of nearfield noise generated by an exhaust nozzle plume. CR. Hixon (1998); used with permission.

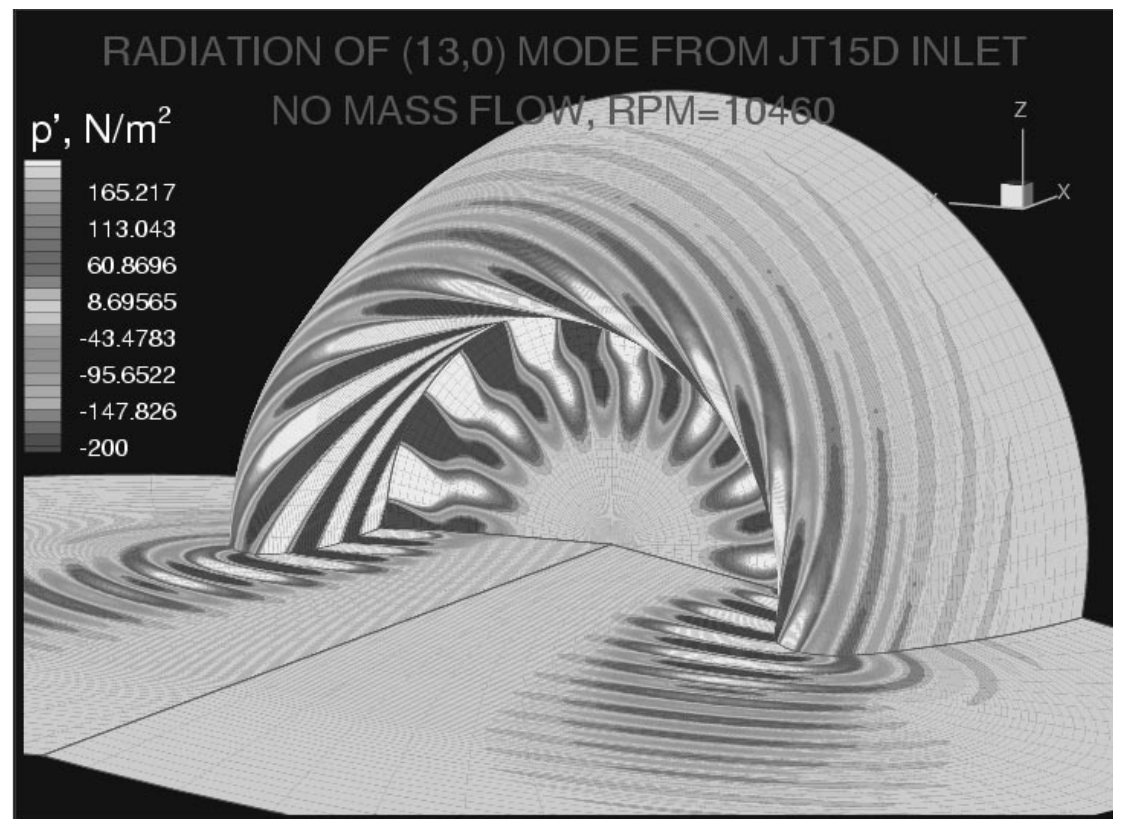

Figure 16. Engine inlet radiation calculated using 3D Euler equations. CL. Long (1998); used with permission. 


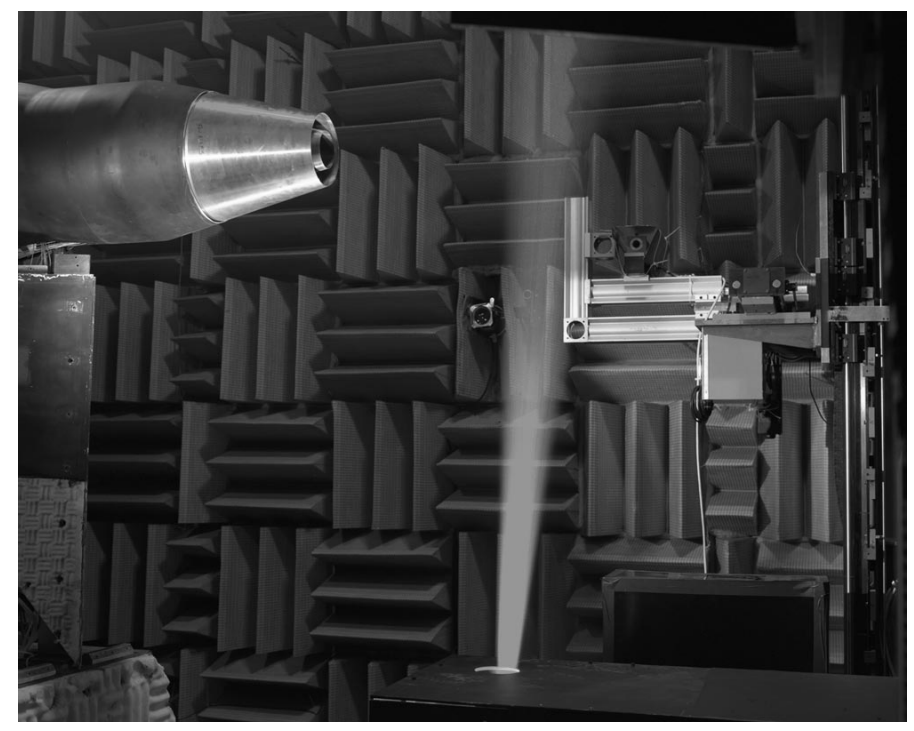

Figure 17. Particle-image-velocimetry setup in the NASA Langley low speed aeroacoustic wind tunnel. Photo courtesy of NASA. 


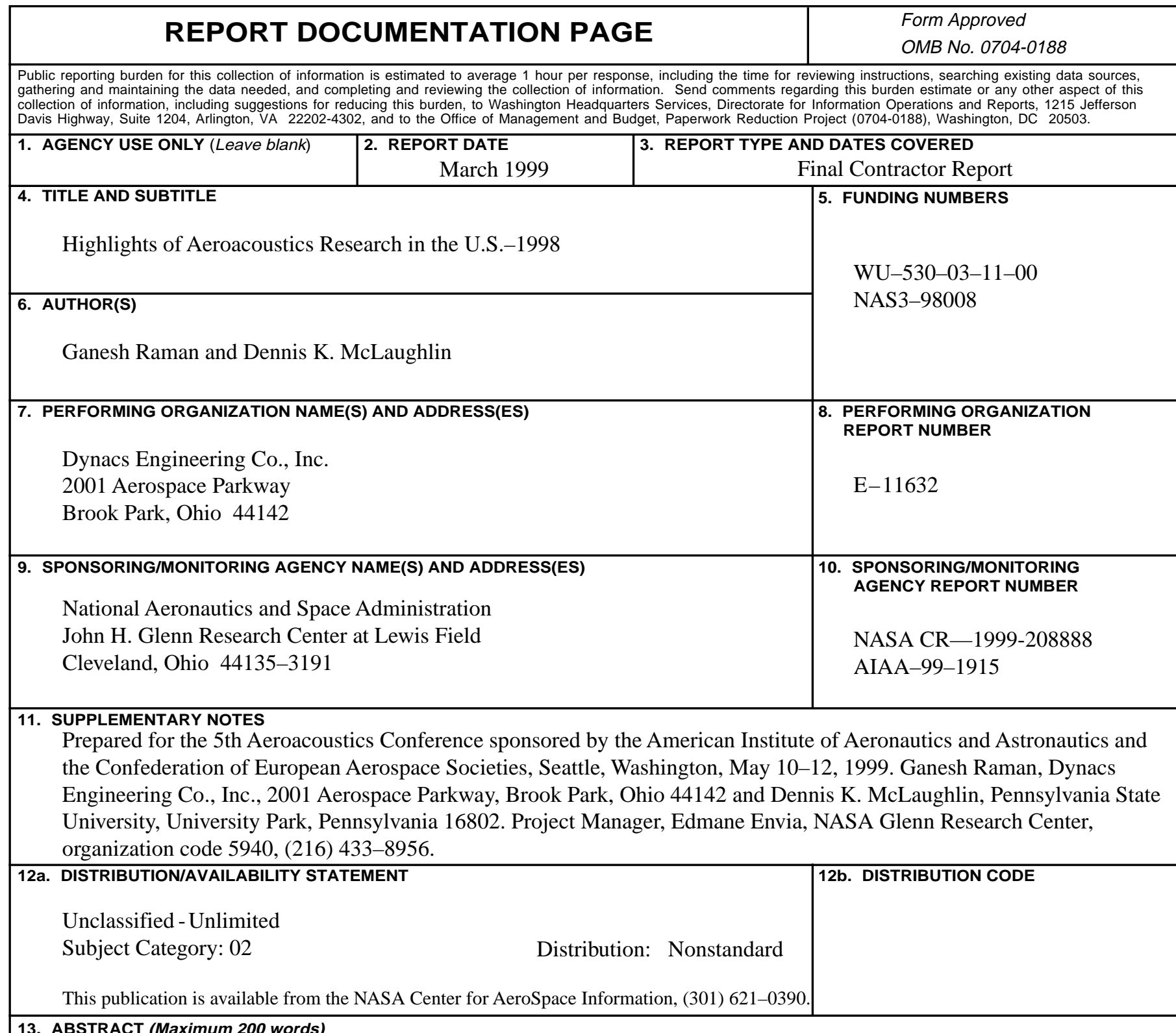

\section{ABSTRACT (Maximum 200 words)}

Highlights of aeroacoustics research in the United States of America during 1998 are reported in a summary compiled from information provided by members of the Aeroacoustics Technical Committee of the American Institute of Aeronautics and Astronautics (AIAA) and other leading research groups in industry, national laboratories, and academia. The past few years have seen significant progress in aeroacoustics. Research has steadily progressed toward enhanced safety, noise benefits, and lower costs. Since industrial progress is generally not published in the archival literature, it is particularly important to highlight these accomplishments. This year we chose to report on five topics of great interest to the aerospace industry including a synopsis of fundamental research at universities and national laboratories. The topics chosen are: (1) Advanced Subsonic Technology (AST), (2) High Speed Research (HSR), (3) Rotorcraft, (4) Weapons bay aeroacoustics control and (5) Academic research including Computational AeroAcoustics (CAA). Although the information presented in this review is not all encompassing we hope that the topics covered will provide some insights into aeroacoustics activity in the U.S.

\begin{tabular}{|c|c|c|}
\hline \multicolumn{3}{|l|}{$\begin{array}{l}\text { 14. SUBJECT TERMS } \\
\text { Aeroacoustics; Highlights }\end{array}$} \\
\hline $\begin{array}{l}\text { 17. SECURITY CLASSIFICATION } \\
\text { OF REPORT } \\
\text { Unclassified }\end{array}$ & $\begin{array}{l}\text { 18. SECURITY CLASSIFICATION } \\
\text { OF THIS PAGE } \\
\text { Unclassified }\end{array}$ & $\begin{array}{l}\text { 19. SECURITY CLASSIFICATION } \\
\text { OF ABSTRACT } \\
\text { Unclassified }\end{array}$ \\
\hline
\end{tabular}

